http://jmscr.igmpublication.org/home/

ISSN (e)-2347-176x ISSN (p) 2455-0450

crossref DOI: https://dx.doi.org/10.18535/jmscr/v7i9.11

\title{
Lifestyle Behaviour of People with Type 2 Diabetes in a Tertiary Care Hospital of Delhi: An Observational Study
}

\author{
Authors
}

\author{
Dr Prakash Ranjan ${ }^{1}$, Dr Abhishek Singh ${ }^{2}$, Dr Urvashi ${ }^{3}$ \\ ${ }^{1}$ The National Institute of Health and Family Welfare, New Delhi \\ ${ }^{2}$ GMC, Nagpur \\ ${ }^{3}$ UCMS, Tribhuvan University, Nepal \\ *Corresponding Author \\ Dr Prakash Ranjan
}

The National Institute of Health and Family Welfare, Baba Gangnath Marg, Munirka, New Delhi 110067

\begin{abstract}
Knowing the lifestyle behaviour and sociodemographic patterns of the diabetes is important not only to understand the underlying etiologies and pathogenetic mechanisms but also successful treatment strategies to manage diabetes in India. In this study, attempt has been made to explore the lifestyle behaviour of patients with type 2 diabetes mellitus with respect to their sociodemographic characteristics. This descriptive and cross sectional study systematic random sampling technique was used to select the sample of type 2 diabetic patients with inclusion criteria patients with confirmed type 2 diabetes mellitus and aged 18 years or older, patients attending outpatient department of a tertiary care hospital in New Delhi and who give consent to be a part of the study and exclusion criteria those patients who are seriously ill or have been advised admission in the hospital. For collection of data a self-developed validated semi structured questionnaire was prepared. Scheduled interview of 412 type 2 diabetic patient was conducted between 24th September 2018 to 31st December 2018 at outpatient department of a tertiary care hospital in New Delhi. The lifestyle behaviour showed out of 412 diabetic patients 35.4 percent were smoker, 28.8 percent had drinking behaviour, 32.7 percent were vegetarian, 51.9 percent had regular walking behaviour and 58.7 percent feel depression or anxiety when they think about diabetes. In conclusion, the study results show that there exists a significant statistical association between sociodemographic characteristics and lifestyle behavior of type 2 diabetes mellitus patients.

Keywords: Lifestyle behaviour, Type 2 Diabetes Mellitus, Sociodemographic Characteristics.
\end{abstract}

\section{Introduction}

Diabetes mellitus (DM) has been one of the leading chronic diseases worldwide over the past decades (WHO). The burden of diabetes has steadily increased over the past quarter century in India and across the globe, with India contributing a major part of the global burden. Among the factors contributing to the increasing incidence of Diabetes mellitus include sedentary lifestyle, obesity and population ageing. Diabetes mellitus complications increase morbidity and mortality and consequently decrease the health-related quality of life. Hence, the complications not only affect physical and mental functioning and patient's well-being, this also increases the overall healthcare costs of each country.

At present, India is experiencing rapid socioeconomic growth that is paralleled by a massive increase in diabetes prevalence. The number of people with diabetes in India increased 
from 26.0 million in 1990 to 65.0 million in $2016 .{ }^{[1]}$ The prevalence of diabetes in adults aged 20 years or older in India increased from 5.5\% (4.9-6.1) in 1990 to $7.7 \%(6.9-8.4)$ in $2016 .^{[1]}$ Rapid economic growth is linked to epidemiological transitions associated with increased life expectancy, lifestyle changes, affluence associated with dietary excess, reduced physical activity and unplanned urbanization, ${ }^{[2]}$ resulting in higher prevalence of diabetes among Indian population. ${ }^{[3]}$

The components of lifestyle behaviour relevant to health include physical activities, diet pattern, sleeping pattern, smoking behaviour, drinking behaviour and psychosocial characteristics. Lifestyle management is a fundamental aspect of diabetes care and includes diabetes selfmanagement education and support (DSMES), medical nutrition therapy (MNT), physical activity, smoking cessation counseling and psychosocial care. ${ }^{[4]}$

Recent evidence supports that all individuals, including those with diabetes should be encouraged to reduce the amount of time spent being sedentary (e.g., working at a computer, watching TV) by breaking up bouts of sedentary activity (30 $\mathrm{min}$ ) by briefly standing, walking, or performing other light physical activities. ${ }^{[5][6]}$ Avoiding extended sedentary periods may help prevent type 2 diabetes for those at risk and may also aid in glycemic control for those with diabetes. Eating Patterns, macronutrient distribution and meal planning are important components of lifestyle behaviour. Emphasis should be on healthy eating patterns containing nutrient-dense foods, such as vegetables, fruits, legumes, low-fat dairy, lean meats, nuts, seeds and whole grains, as well as on achieving the desired energy deficit. ${ }^{[7]}$

Smokers with diabetes (and people with diabetes exposed to secondhand smoke) have a heightened risk of cardiovascular disease (CVD), premature death and microvascular complications. Smoking may have a role in the development of type 2 diabetes. ${ }^{[8]}$ Diabetes and alcohol consumption are two of the most dangerous public health problems our country faces. The prevalence of alcohol consumption in India is around $21 \%$ among men and $2 \%$ among women. ${ }^{[9]}$ Alcohol influences glucose metabolism in several ways in diabetic patients as well as in non-diabetic patients. Taken with food alcohol is the preferred fuel and causes higher blood glucose levels leading to insulin response. Since alcohol inhibits both gluconeogenesis and glycogenolysis, its acute intake without food may provoke hypoglycemia, especially in cases of depleted glycogen stores and in combination with sulphonylurea.

Complex environmental, social, behavioural and emotional factors, known as psychosocial factors, influence living with diabetes and achieving satisfactory medical outcomes and psychological well-being. Thus, individuals with diabetes and their families are challenged with complex, multifaceted issues when integrating diabetes care into daily life. Many non-communicable chronic diseases, including type 2 diabetes are highly prevalent and largely preventable. The prevention and management of type 2 diabetes in India requires a combination of lifestyle changes and long-term health-care management. Knowing the lifestyle behaviour and sociodemographic patterns of the disease are important not only to understand the underlying etiologies and pathogenetic mechanisms but also to predict future course of epidemic that would help policymakers to design and implement successful treatment strategies to manage diabetes in India. In this study, attempt has been made to explore the lifestyle behaviour of patients with type 2 diabetes mellitus with respect to their sociodemographic characteristics.

\section{Material and Methods}

The study is descriptive and cross sectional in nature which aimed to explore the lifestyle behaviour of patients with type 2 diabetes mellitus with respect to their sociodemographic characteristics. Systematic random sampling technique was used to select the sample of type 2 diabetic patients. The sample for the present study 
was selected taking into consideration the inclusion Criteria which are patients with confirmed type 2 diabetes mellitus and aged 18 years or older, patients attending outpatient department of a tertiary care hospital in New Delhi and who give consent to be a part of the study and exclusion criteria included those patients who are seriously ill or have been advised admission in the hospital.

The study variables include dependent variable which is diabetes and independent variables which are sociodemographic characteristics such as gender, age, marital status, religion, educational status, occupation, average monthly family income, family size and lifestyle behaviour which includes physical activities, diet pattern, smoking behaviour, drinking behaviour and psychosocial characteristics of the patients with type 2 diabetes. For collection of data a self-developed semi structured questionnaire was prepared based on WHO STEPS Instrument for NCD Risk Factors (Core and Expanded Version 1.4). Scheduled interview of 412 type 2 diabetic patient was conducted between 24th September 2018 to 31st December 2018 at outpatient department of a tertiary care hospital in New Delhi. All data collected from filled up questionnaire were entered into Microsoft Excel 2007 worksheet in the form of a master chart. These data were classified and analyzed using Statistical Package for the Social Sciences (SPSS version 20) as per the aims and objectives of the study. The data on sample characteristics were described in the form of tables. Inferential statistics such as Chi- square test was used to find out the association of sociodemographic characteristics with gender, lifestyle behaviour with gender and lifestyle behaviour with sociodemographic characteristics of type 2 diabetes mellitus patients.

\section{Results}

The sociodemographic characteristics of the study population showed out of 412 diabetic patients, 52.7 percent were males while 47.3 percent were females, maximum 35.7 percent were of 41-50 age group, mostly 95 percent were married and 90 percent were Hindus (Table No. 1). About 16 percent of the study subjects were illiterate and 45.1 percent were educated only up to high school level, about 38.3 percent of the subjects were unemployed and majorities of them 31.3 percent were women engaged as housewives, 74.8 percent diabetic patients had average monthly family income fall below Rs. 20,000 (Table No. 1).

The lifestyle behaviour showed out of 412 diabetic patients 35.4 percent were smoker, 28.8 percent had drinking behaviour, 32.7 percent were vegetarian, 51.9 percent had regular walking behaviour and 58.7 percent feel depression or anxiety when they think about diabetes (Table No. 2).

After assessing, observing and analyzing all the relevant data, the study results show that age of patients, marital status of patients, educational status, occupation and average monthly family income of diabetic patients are statistically associated with gender of the patients. Lifestyle behaviour like smoking behaviour, drinking behaviour and diet pattern are also statistically associated with gender of the diabetic patients.

Prevalence of lifestyle behavior according to sociodemographic characteristics of diabetic patients showed diet pattern, walking behaviour and depression and anxiety behaviour are statistically associated with age of patients. Smoking behaviour, drinking behaviour and diet pattern are statistically associated with marital status of diabetic patients. The diet pattern is statistically associated with religion of diabetic patients. Smoking behaviour, drinking behaviour, diet pattern, walking behaviour and depression or anxiety behaviour are statistically associated with educational status of diabetic patients. Smoking behaviour, drinking behaviour, diet pattern and depression or anxiety behaviour are statistically associated with occupation of diabetic patients. Diet pattern, walking behaviour and depression or anxiety behaviour are statistically associated with average monthly family income of diabetic patients. (Table no. 3) 
Table No. -01 Distribution of sociodemographic characteristics by gender

\begin{tabular}{|c|c|c|c|c|c|c|}
\hline \multirow{2}{*}{$\begin{array}{l}\text { Variables } \\
\text { Age (Years) }\end{array}$} & \multicolumn{2}{|r|}{ Men } & \multicolumn{2}{|c|}{ Women } & \multirow{2}{*}{$\begin{array}{c}\text { Total } \\
\mathrm{n}\end{array}$} & \multirow[t]{2}{*}{ p-Value } \\
\hline & $\mathrm{n}$ & percentage & $\mathrm{n}$ & percentage & & \\
\hline $18-30$ & 1 & $12.5 \%$ & 7 & $87.5 \%$ & 8 & \multirow[t]{5}{*}{$<0.001$} \\
\hline $31-40$ & 26 & $37.5 \%$ & 43 & $62.3 \%$ & 69 & \\
\hline $41-50$ & 76 & $51.7 \%$ & 71 & $48.3 \%$ & 147 & \\
\hline $51-60$ & 57 & $52.8 \%$ & 51 & $47.2 \%$ & 108 & \\
\hline$>60$ & 57 & $71.2 \%$ & 23 & $28.7 \%$ & 80 & \\
\hline \multicolumn{7}{|l|}{ Marital Status } \\
\hline Married & 214 & $54.7 \%$ & 177 & $45.3 \%$ & 391 & \multirow[t]{2}{*}{$<0.001$} \\
\hline Unmarried/Widowed & 3 & $14.3 \%$ & 18 & $85.7 \%$ & 21 & \\
\hline \multicolumn{7}{|l|}{ Religion } \\
\hline Hindu & 194 & $52.6 \%$ & 175 & $47.4 \%$ & 369 & \multirow[t]{2}{*}{0.910} \\
\hline Others & 23 & $53.5 \%$ & 20 & $46.5 \%$ & 43 & \\
\hline \multicolumn{7}{|l|}{ Educational Status } \\
\hline Graduate degree and above & 54 & $71.1 \%$ & 22 & $28.9 \%$ & 76 & \multirow[t]{6}{*}{$<0.001$} \\
\hline Higher secondary certificate & 57 & $67.9 \%$ & 27 & $32.1 \%$ & 84 & \\
\hline High school certificate & 38 & $54.3 \%$ & 32 & $45.7 \%$ & 70 & \\
\hline Middle school certificate & 28 & $50.9 \%$ & 27 & $49.1 \%$ & 55 & \\
\hline Literate, less than Middle school certificate & 27 & $44.3 \%$ & 34 & $55.7 \%$ & 61 & \\
\hline Illiterate & 13 & $19.7 \%$ & 53 & $80.3 \%$ & 66 & \\
\hline \multicolumn{7}{|l|}{ Occupation } \\
\hline Semi-profession & 26 & $70.3 \%$ & 11 & $29.7 \%$ & 37 & \multirow{6}{*}{$<0.001$} \\
\hline Clerical, Shop-owner & 81 & $77.9 \%$ & 23 & $22.1 \%$ & 104 & \\
\hline Skilled worker & 36 & $78.3 \%$ & 10 & $21.7 \%$ & 46 & \\
\hline Semi-skilled worker & 27 & $90.0 \%$ & 3 & $10.0 \%$ & 30 & \\
\hline Unskilled worker & 18 & $48.6 \%$ & 19 & $51.4 \%$ & 37 & \\
\hline Unemployed & 29 & $18.4 \%$ & 129 & $81.6 \%$ & 158 & \\
\hline \multicolumn{7}{|l|}{ Average Monthly Family Income (Rs.) } \\
\hline$<10000$ & 43 & $40.2 \%$ & 64 & $59.8 \%$ & 107 & \multirow[t]{5}{*}{$\mathbf{0 . 0 3 3}$} \\
\hline $10000-20000$ & 110 & $54.7 \%$ & 91 & $45.3 \%$ & 201 & \\
\hline $20000-30000$ & 39 & $62.9 \%$ & 23 & $37.1 \%$ & 62 & \\
\hline $30000-40000$ & 17 & $60.7 \%$ & 11 & $39.3 \%$ & 28 & \\
\hline$\geq 40000$ & 08 & $57.1 \%$ & 06 & $42.9 \%$ & 14 & \\
\hline
\end{tabular}

$\mathrm{p}$ Value $\leq 0.05=$ Significant

Table No. -02 Prevalence of lifestyle behavior by gender

\begin{tabular}{|c|c|c|c|c|c|c|}
\hline Variables & \multicolumn{2}{|c|}{ Men } & \multicolumn{2}{|c|}{ Women } & Total & \multirow[t]{2}{*}{ p-Value } \\
\hline Age (Years) & $\mathrm{n}$ & percentage & $\mathrm{n}$ & percentage & $\mathrm{n}$ & \\
\hline Smoking & 127 & $87 \%$ & 19 & $13 \%$ & 146 & $<0.001$ \\
\hline Drinking & 111 & $93.3 \%$ & 8 & $6.7 \%$ & 119 & $<0.001$ \\
\hline Diet Pattern & 53 & $39.3 \%$ & 82 & $60.7 \%$ & 135 & $<0.001$ \\
\hline Regular Walking & 116 & $54.2 \%$ & 98 & $45.8 \%$ & 214 & 0.516 \\
\hline Depression/ Anxiety & 125 & $51.7 \%$ & 117 & $48.3 \%$ & 242 & 0.677 \\
\hline
\end{tabular}

Table No. -03 Prevalence of lifestyle behavior according to sociodemographic characteristics

\begin{tabular}{|l|c|c|c|c|c|}
\hline Variables & Smoking & Drinking & Diet(Vegetarian) & $\begin{array}{c}\text { Regular } \\
\text { Walking }\end{array}$ & $\begin{array}{c}\text { Depression/ } \\
\text { Anxiety }\end{array}$ \\
\hline Age (Years) & \multicolumn{5}{|l|}{} \\
\hline $18-30$ & $1(0.7 \%)$ & $02(1.7 \%)$ & $01(0.7 \%)$ & $4(1.9 \%)$ & $3(1.2 \%)$ \\
\hline $31-40$ & $21(14.3 \%)$ & $20(16.8 \%)$ & $17(12.6 \%)$ & $23(10.7 \%)$ & $25(10.3 \%)$ \\
\hline $41-50$ & $64(43.5 \%)$ & $49(41.2 \%)$ & $41(30.4 \%)$ & $76(35.5 \%)$ & $86(35.5 \%)$ \\
\hline $51-60$ & $37(25.2 \%)$ & $27(22.7 \%)$ & $37(27.4 \%)$ & $66(30.8 \%)$ & $78(32.2 \%)$ \\
\hline$>60$ & $24(16.3 \%)$ & $21(17.6 \%)$ & $39(28.9 \%)$ & $45(21 \%)$ & $50(20.7 \%)$ \\
\hline p- value & 0.096 & 0.638 & $\mathbf{0 . 0 0 6}$ & $\mathbf{0 . 0 0 8}$ & $<\mathbf{0 . 0 0 1}$ \\
\hline
\end{tabular}




\begin{tabular}{|c|c|c|c|c|c|}
\hline \multicolumn{6}{|l|}{ Marital Status } \\
\hline Married & $143(97.9 \%)$ & $118(99.2 \%)$ & $124(91.9 \%)$ & $205(95.8 \%)$ & $227(93.8 \%)$ \\
\hline Unmarried/Widowed & $3(2.1 \%)$ & $1(0.8 \%)$ & $11(8.1 \%)$ & $9(4.2 \%)$ & $15(6.2 \%)$ \\
\hline p- value & 0.038 & 0.012 & 0.049 & 0.392 & 0.381 \\
\hline \multicolumn{6}{|l|}{ Religion } \\
\hline Hindu & $134(91.8 \%)$ & $106(89.1 \%)$ & $134(99.3 \%)$ & $196(91.6 \%)$ & $217(89.7 \%)$ \\
\hline Others & $12(8.2 \%)$ & $13(10.9 \%)$ & $1(0.7 \%)$ & $18(8.4 \%)$ & $25(10.3 \%)$ \\
\hline $\mathrm{p}$-value & 0.275 & 0.837 & $<0.001$ & 0.162 & 0.785 \\
\hline \multicolumn{6}{|l|}{ Educational Status } \\
\hline Graduate degree and above & $27(18.5 \%)$ & $26(21.8 \%)$ & $26(19.3 \%)$ & $42(19.6 \%)$ & $40(16.5 \%)$ \\
\hline Higher secondary certificate & $42(28.8 \%)$ & $31(26.1 \%)$ & $35(25.9 \%)$ & $50(23.4 \%)$ & $52(21.5 \%)$ \\
\hline High school certificate & $27(18.5 \%)$ & $21(17.6 \%)$ & $32(23.7 \%)$ & $28(13.1 \%)$ & $54(22.3 \%)$ \\
\hline Middle school certificate & $22(15.1 \%)$ & $24(20.2 \%)$ & $14(10.4 \%)$ & $22(10.3 \%)$ & $30(12.4 \%)$ \\
\hline $\begin{array}{l}\text { Literate, less than Middle } \\
\text { school certificate }\end{array}$ & $14(9.6 \%)$ & $10(8.4 \%)$ & $8(5.9 \%)$ & $41(19.2 \%)$ & $30(12.4 \%)$ \\
\hline Illiterate & $14(9.6 \%)$ & $7(5.9 \%)$ & $20(14.8 \%)$ & $31(14.5 \%)$ & $36(14.9 \%)$ \\
\hline p-value & 0.002 & $<0.001$ & 0.001 & 0.008 & $<0.001$ \\
\hline \multicolumn{6}{|l|}{ Occupation } \\
\hline Semi-profession & $18(12.3 \%)$ & $15(12.6 \%)$ & $13(9.6 \%)$ & $23(10.7 \%)$ & $22(9.1 \%)$ \\
\hline Clerical, Shop owner & $58(39.7 \%)$ & $46(38.7 \%)$ & $37(27.4 \%)$ & $56(26.2 \%)$ & $68(28.1 \%)$ \\
\hline Skilled worker & $19(13 \%)$ & $21(17.6 \%)$ & $7(5.2 \%)$ & $22(10.3 \%)$ & $26(10.7 \%)$ \\
\hline Semi-skilled worker & $15(10.3 \%)$ & $16(13.4 \%)$ & $2(1.5 \%)$ & $13(6.1 \%)$ & $12(5 \%)$ \\
\hline Unskilled worker & $16(11 \%)$ & $10(8.4 \%)$ & $7(5.2 \%)$ & $14(6.5 \%)$ & $14(5.8 \%)$ \\
\hline Unemployed & $20(13.7 \%)$ & $11(9.2 \%)$ & $69(51.1 \%)$ & $86(40.2 \%)$ & $100(41.3 \%)$ \\
\hline p-value & $<0.001$ & $<0.001$ & $<0.001$ & 0.283 & 0.05 \\
\hline \multicolumn{6}{|l|}{$\begin{array}{l}\text { Average Monthly Family } \\
\text { Income(Rs.) }\end{array}$} \\
\hline$<10000$ & $36(24.7 \%)$ & $23(19.3 \%)$ & $26(19.3 \%)$ & $56(26.2 \%)$ & $49(20.2 \%)$ \\
\hline $10000-20000$ & $74(50.7 \%)$ & $67(56.3 \%)$ & $71(52.6 \%)$ & $88(41.1 \%)$ & $132(54.5 \%)$ \\
\hline $20000-30000$ & $20(13.7 \%)$ & $15(12.6 \%)$ & $27(20 \%)$ & $37(17.3 \%)$ & $32(13.2 \%)$ \\
\hline $30000-40000$ & $11(7.5 \%)$ & $8(6.7 \%)$ & $10(7.4 \%)$ & $24(11.2 \%)$ & $18(7.4 \%)$ \\
\hline$\geq 40000$ & $5(3.4 \%)$ & $6(5 \%)$ & $1(0.7 \%)$ & $9(4.2 \%)$ & $11(4.5 \%)$ \\
\hline p-value & 0.942 & 0.148 & 0.02 & $<0.001$ & 0.011 \\
\hline
\end{tabular}

$\mathrm{p}$ Value $\leq 0.05=$ Significant

\section{Discussion}

Diabetes mellitus is a major public health problem worldwide. Its prevalence is on the rise in many parts of the developing countries including India. Individuals with Type 2 diabetes mellitus are considered as high priority as they are potential candidates for rapid evaluation to prevent and halt the progression of the complications.

The study findings document that there were 52.7 percent of male and 47.3 percent of female patients having type 2 diabetes mellitus. This indicates that there is little variation in terms of prevalence of diabetes based on gender which is in consistent with the study findings of Ramachandran et al. ${ }^{[11]}$ who also reported that the prevalence of diabetes seems to be more or less same in both the genders. The age wise prevalence of diabetes among the patients is found to be 18.6 percent for 18-40 years, 35.7 percent for $41-50$ years, 26.2 percent for 51-60 years and 19.4 percent for more than 60 years, which is similar to the findings of Anjana et al. ${ }^{[10]}$ who reported high prevalence of diabetes among people between 25 34 years age with a decline after age 65 years. Koria et al. ${ }^{[12]}$ in their study also found majority of diabetic population (53.64\%) was between 45 60 years but there was fall in the number of diabetic patients after 60 years of age. This may be due to elderly people are less mobile and less reporting themselves at hospitals for diabetes diagnosis and management. It is also observed that 16 percent of the study subjects were illiterate and 45.1 percent were educated only up to high school level which is similar to the findings by 
Rubin et al. ${ }^{[13]}$ who observed that education appears to have a major effect on diabetes prognosis. Whether this was related to greater understanding of the illness and therefore greater commitment to self care and therefore better access to medical care, or both, was difficult to say.

In the present study it is found that only 9 percent of diabetic patients have semi professional and professional occupation which is in consistent with the result of Arora et al. ${ }^{[14]}$ and Patil and Gothankar $^{[15]}$, where they found a significant association between the occupation and risk status of diabetes. This suggests that diabetes is no longer a disease of the affluent, or a "rich man's disease". It is becoming a problem even among the middle-income and poorer sections of the society. This may be due to changes in the lifestyle and standard of living of people from urban slum areas, as a result of urbanization. However, Mohan et al. ${ }^{[16]}$ found a significant association between diabetes and higher socioeconomic class as well. Based on above stated finding it can be stated that there are 74.8 percent diabetic patients whose average monthly family income fall below Rs. 20,000 which is in consistent with the finding by Rayappa et al. ${ }^{[10]}$ and Williams et al. ${ }^{[17]}$ who showed higher prevalence of diabetes among lower family income group. In addition, Kinge and Supe ${ }^{[18]}$ in their study also found higher prevalence of diabetes among lower family income class. The regular walking behaviour is $12.6 \%$ in 18 to 40 year age group, $66.3 \%$ in 40 to 60 year age group and $21 \%$ in diabetic patients above 60 years age group which is similar to the findings by Brugnara et al. ${ }^{[19]}$ who showed at early (18-30 years) and advanced (> 60 years) ages diabetic patient walking behaviour is lesser as compared to 30 to 60 year age group. The result of the present study shows that smoking behaviour, drinking behaviour, vegetarian diet and feeling of depression or anxiety when they think about diabetes is more among patients with lower educational status, middle age group (40 to 60 years) and average monthly family income upto 20,000 Rs. which is in consistent with study of Wardle and Steptoe ${ }^{[20]}$. Higher family income increases the likelihood of proper care being provided to persons with diabetes. More so if the affected family member is actively working (gainfully employed or a housewife). This greater care should translate into fewer diabetes related complications.

A limitation of the present study is that diet, alcohol, smoking, physical activity and feeling of depression and anxiety were all self-reported. Since this study was conducted in a government tertiary care hospital, hence comparison with private hospital is not possible as patients in these facilities may differ in their sociodemographic characteristics. As the study findings are based on the data collected from only one government tertiary care hospital located in New Delhi with limited sample size and therefore result of the study may not be considered for broader generalization and application.

In conclusion, these results show that there exists a significant statistical association between sociodemographic characteristics and lifestyle behavior of type 2 diabetes mellitus patients. Shifting the sociodemographic characteristics in the adult population could have an important impact on the lifestyle of type 2 diabetes and, as a consequence, complications of diabetes. More action is needed for improved diabetes selfmanagement among those living with the disease with lower socioeconomic status, and those patients who continue to drink, smoke, lesser walking behaviour and more feeling of depression or anxiety when think about diabetes. Provision of information and advice for lifestyle behavior at the primary care level, and targeted to these higher risk groups, may be an effective health promotion strategy. Hence, after reviewing literature, it can be said that in future, more variable specific research is required, especially focusing on factors affecting lifestyle behaviour which further affects physical or mental health of the individual. Thus, it would be appropriate to suggest that prevention 
of diabetes is need of an hour, and this objective can be achieved by empowering patients, health professionals, and family members regarding importance of good and healthy life.

\section{Ethics approval and consent to participate:}

Written informed consent was obtained from all the study participants and ethical approval was granted by the National Institute of Health and Family Welfare, New Delhi.

\section{Competing interests:}

None of the authors of this paper have financial or non-financial competing interests with regards to the content of this paper.

Financial support and sponsorship: Nil.

\section{Authors' contributions:}

PR contributed to the study concept, design, conduct of the study, interpretation of the data and preparation of the manuscript. AS and $\mathrm{U}$ contributed to the statistical analysis and interpretation of the data.

\section{Acknowledgments}

It is my proud privilege to express my deep sense of gratitude to Director and Dean of studies, The National Institute of Health and Family Welfare, Munirka, New Delhi, for their constant support, motivation, guidance and help throughout the study. I also express my sincere thanks to all the faculty members of NIHFW for their constant help and encouragement to carry out the study. My sincere thanks to Director (MS), Charak Palika Hospital, New Delhi for allowing me to carry out this study.

\section{References}

1. India State-Level Disease Burden Initiative Diabetes Collaborators. The increasing burden of diabetes and variations among the states of India: the Global Burden of Disease Study 19902016. Lancet Glob Health. 2018; 6(12):e1352-e1362. (accessed October 17, 2018)

2. Ramachandran A, Snehalatha C, Kapur A, Vijay V, Mohan V, Das AK, et al. High prevalence of diabetes and impaired glucose tolerance in India: National Urban Diabetes Survey. Diabetologia2001; 44:1094-101. (accessed May 5, 2019)

3. Jayawardena R, Ranasinghe P, Byrne NM, Soares MJ, Katulanda P, Hills AP. Prevalence and trends of the diabetes epidemic in South Asia: A systematic review and meta-analysis. BMC Public Health 2012; 12:380. (accessed March 14, 2019)

4. American Diabetes Association. 4. Lifestyle management: Standards of Medical Care in Diabetesd2018. Diabetes Care 2018;41(Suppl. 1): S38-S50. (accessed October 15, 2018)

5. Katzmarzyk PT, Church TS, Craig CL, Bouchard C. Sitting time and mortality from all causes, cardiovascular disease, and cancer. Med Sci Sports Exerc 2009; 41:998-1005. (accessed May 2, 2018)

6. Dempsey PC, Larsen RN, Sethi P, et al. Benefits for type 2 diabetes of interrupting prolonged sitting with brief bouts of light walking or simple resistance activities. Diabetes Care 2016;39:964- 972. (accessed July 19, 2019)

7. Sacks FM, Bray GA, Carey VJ, et al. Comparison of weight-loss diets with different compositions of fat, protein, and carbohydrates. N Engl J Med 2009;360:859-873. (accessed October 4, 2018)

8. Jankowich M, Choudhary G, Taveira TH, Wu W-C. Age-, race-, and gender-specific prevalence of diabetes among smokers. Diabetes Res Clin Pract 2011;93: e101e105. (accessed July 12, 2019)

9. Raekha Prasad. Alcohol on the rise in India. Lancet medical journal vol 373 Jan 2009

10. Anjana, R.M., Pradeepa, R., Deepa, M. et al. Diabetologia (2011) 54: 3022. https://doi.org/10.1007/s00125-011-22915 (accessed June 2, 2019) 
11. Ramachandran A, Snehalatha C, Kapur A, Vijay V, MohanV, Das AK, et al. Diabetes Epidemiology Study Group inIndia (DESI). High prevalence of diabetes and impairedglucose tolerance in India: National Urban Diabetes Survey. Diabetologia 2001; 44 : 1094-101.14. (accessed October 5, 2018)

12. Koria B, Kumar R, Nayak A, Kedia G. Prevalence of Diabetes Mellitus in Urban Population of Ahmadabad City, Gujarat. Natl J Community Med 2013; 4(3): 398401. (accessed May 29, 2019)

13. Richard R Rubin, PhD, Mark Peyrot, PhD and Christopher D Saudek, MD. Differential Effect of Diabetes Education on Self-Regulation and Life-Style Behaviours. Diabetes Care 1991 Apr; 14(4):

335-337. https://doi.org/10.2337/diacare.14.4.335. (accessed September 1, 2018)

14. Arora, V., Malik, J.S, Khanna, P., Goyal, N. Kumar, N. Singh, M. Prevalence of Diabetes in urban Haryana.AMJ 2010, 3, 8, 488-494. Doi 10.4066/AMJ.2010.410. (accessed April 7, 2019)

15. Patil RS, Gothankar JS. Assessment of risk of type 2 diabetes using the Indian Diabetes Risk Score in an urban slum of Pune, Maharashtra, India: a cross-sectional study. WHO South-East Asia J Public Health 2016; 5(1): 53-61. (accessed May 5, 2019)

16. Mohan V, Deepa M, Deepa R, Shantirani CS, Farooq S, Ganesa A et al. Secular trends in prevalence of diabetes and glucose tolerance in urban south India the Chennai urban rural epidemiology study (CURES 17). Diabetologia. 2006; 49(6):1175-8. (accessed October 3, 2018)
17. E. D. Williams \& R. J. Tapp \& D. J. Magliano \& J. E. Shaw \& P. Z. Zimmet \& B. F. Oldenburg/ Health behaviours, socioeconomic status and diabetes incidence: the Australian Diabetes Obesity and Lifestyle Study (AusDiab)/ Diabetologia (2010) 53:2538-2545/ DOI 10.1007/s00125-010-1888-4. (accessed March 17, 2019)

18. Kirti Kinge and Amit Supe / Association between socioeconomic status and Diabetes Mellitus in Perimenopausal Women. International Journal of Biomedical and Advance Research 2015; 6(12): 853-855. (accessed October 2, 2018)

19. Brugnara L, Murillo S, Novials A, RojoMartínez G, Soriguer F, Goday A, et al. (2016) Low Physical Activity and Its Association with Diabetes and Other Cardiovascular Risk Factors: A Nationwide, Population-Based Study. PLoS ONE 11(8): e0160959. doi: 10.1371/journal.pone.0160959. (accessed October 5, 2018)

20. Wardle J, Steptoe A. Socioeconomic differences in attitudes and beliefs about healthy lifestyles. J Epidemiol Community Health. 2003;57(6):440-443. doi:10.1136/jech.57.6.440. (accessed January 12, 2019). 